Rahardjo, W., Mulyani, I., Andriani, I., Qomariyah, N. (2020). Factors influencing employee's quality of life during COVID-19 pandemic. Indigenous: Jurnal Ilmiah Psikologi, 5(2). 164-174. doi: https://doi.org/10.23917/indigenous.v5i2.11086

\title{
Factors Influencing Employee's Quality of Life During COVID-19 Pandemic
}

\author{
Wahyu Rahadjo ${ }^{1}$, Indah Mulyani ${ }^{2}$, Inge Andriani ${ }^{3}$, Nurul Qomariyah $^{4}$ \\ Porgram Studi Psikologi, Fakultas Psikologi, Universitas Gunadarma ${ }^{1,2,3,4}$ \\ wahyu_r@staff.gunadarma.com ${ }^{1}$, indah.mul@gmail.com², \\ inge_andriani@staff.gunadarma.ac.id ${ }^{3}$,nurul_q@staff.gunadarma.ac.id ${ }^{4}$
}

\begin{tabular}{|l|l|l|}
\hline Submitted: 8 June 2020 & Accepted: 8 Oktober 2020 & Published: 30 November 2020 \\
\hline
\end{tabular}

Abstract. One result of the COVID-19 pandemic for the broader community, especially employees, is the need to carry out physical distancing in the form of work from home. This phenomenon certainly has consequences on their quality of life. The purpose of this study was to determine whether employees' quality of life who worked from home was influenced by variables such as type D personality, anxiety, technology overload, and work-life balance. Participants in this study were 486 employees living in Jakarta Greater Area who worked from home because of the COVID-19 pandemic. Participants were recruited by purposive sampling utilizing an online questionnaire. Measurements were made using a measuring tool from each variable employing a quantitative approach. Hierarchical regression was used as a data analysis technique. This research's findings revealed that all independent variables influenced the quality of life. However, anxiety had the smallest influence, and type D personality had the most significant effect. Meanwhile, like work-life balance, technology overload positively affected the quality of life. It implies that internal and external factors could have different effects on the quality of life felt by employees who worked from home due to the COVID-19 pandemic.

Keywords: COVID-19 pandemic; employee; quality of life

\section{INTRODUCTION}

A new coronavirus case $(2019-\mathrm{nCoV})$ first appeared in Wuhan, China, in December 2019 and was later named by WHO as COVID-19 (WHO, 2020). COVID-19 then went into a pandemic and infected many of the world's population. One of the policies adopted in many countries, including Indonesia, as a strategy to deal with the spread of the virus, is the physical distancing policy. Physical distancing is a policy of maintaining physical distance during communication between individuals required by WHO to be implemented in dealing with the spread of COVID-19 (Bueno, 2020).

Work from home is the implementation of the physical distancing policy emphasized by the Indonesian government to ministries, state-owned enterprises, and private companies to their private employees and civil servants. As encountered in the COVID-19 pandemic period, the work from home situation was alluded to a dozen years ago. Previously, it was stated that the digital workspace concept is considered to be one of the phenomena that will occur widely in the industrial world (Benson et al., 2002). 
Meanwhile, the COVID-19 pandemic has negative consequences on mental health issues. Xiang et al. (2020) stated that the primary substance was not only related to the physical health of people affected by COVID-19 but also to mental health. Mental health problems because of lockdown during the COVID-19 epidemic appears in the community regardless of occupational background and age group, and it emerges in various forms of depression and self-endangering behaviors (Ahmed et al., 2020; Huang \& Zhao, 2020; Wang et al., 2020).

One of the mental health problems associated with work from home activities and epidemics of certain diseases such as COVID-19 is quality of life (Ping et al., 2020). Quality of life is overall general well-being, consisting of objective descriptors and subjective evaluations of physical, material, social, and emotional well-being plus levels of personal development and purposeful activity, all of which are considered by a set of personal values (Karimi \& Brazier, 2016). Besides, economic conditions that are very uncertain because of the crisis have caused employees to experience mental health problems and quality of life problems (Drydakis, 2015). Kramer and Kramer (2020) said that the impact of the Covid-19 pandemic, however, is widespread and may result in not only the temporal disappearance of some occupations and dramatic growth in other occupations but also the changes in the status of some occupations and their value proposition. Thus, the COVID-19 epidemic has consequences for many aspects of life, affecting individuals' quality of life in society.

The variable said to have a strong influence on the quality of life is the Type $\mathrm{D}$ personality. Type $\mathrm{D}$ personality is a personality trait prone to causing psychological stress due to negative emotions and a tendency to withdraw from social interactions (Denollet, 2005; Denollet et al., 2010). Individuals with type $D$ personality find it easier to feel stressed when dealing with various life difficulties (O'Riordan et al., 2020). The perceived effect can even appear in various physical symptoms, followed by poor coping strategies (Williams \& Wingate, 2012). As a result, the individual becomes more difficult to enjoy life and considers existing difficulties as pressure. In this case, the current condition of work from home is described as the changes in the status of some occupations and their value propositions. It certainly puts pressure on employees, coupled with the uncertainty of current economic conditions, especially those who are married. In fact, type $\mathrm{D}$ personality does not only affect the quality of life of people with illness but also healthy people (Stevenson \& Williams, 2014). Therefore, employees with type D personality tendencies whose lives are affected by COVID-19 and work from home are likely to be severely disrupted by the quality of life.

Another thing that is also thought to affect the quality of life is anxiety. Anxiety is said to be one of the most common mental health problems found in communities throughout the world and from various age groups (Craske $\&$ Stein, 2016). At least about $11 \%$ of the world's population experiences anxiety every year as a personal failure to respond to the pressures of events that are considered scary experiences (Craske \& Stein, 2016; Tomasi et al., 2019). Anxiety in this study is anxiety associated with COVID-19. Uncertain conditions that are considered to threaten life and resources to survive give rise to many anxiety symptoms in various groups in the world community (Baloran, 2020; S. A. Lee, 2020; Torales et al., 2020). Anxiety-related to COVID-19 is one of the first mental health problems that has attracted the attention of some researchers in conducting initial researches related to measuring tools and other consequences or solutions to psychological problems due to pandemics (Ahorsu et al., 2020; Lee, 2020; Torales et al., 2020; Wang et al., 2020).

Moreover, work from home certainly requires the involvement of technology to break the distance and gain time effectiveness. However, it can be considered burdensome because 
technology is the main thing used to do work, whereas previously, it might only be a supporting factor. It leaves individuals vulnerable to technology overload. Technology overload is a situation when information technology forces individuals to work faster and longer while completing tasks in daily activities, causing cognitive and physical burdens (Tarafdar et al., 2007). Thus, work from home with the use of technology can have many negative consequences. Excessive use of technology when working can take up much individual time, cause stress and conflict with others, including with family, reduce interaction in the family, and influence well-being (Fiksenbaum, 2014; Tams et al., 2020; Tarafdar et al., 2010). Therefore, technology overload can also affect the quality of life of individuals in various aspects.

Besides, another variable that is also thought to impact the quality of life is work-life balance. Work-life balance itself has long been a concern of researchers because it is related to well-being and mental health (Haar et al., 2014; Wagner et al., 2014). Work-life balance is the same degree of individual satisfaction when undergoing various roles related to work and life at home (Wood et al., 2020). Individuals who can develop work-life balance usually have good communication with family during work, including time management and self-care abilities (Bisschoff et al., 2019). These things certainly minimize conflict and pressure and help achieve a quality of life.

Previous research related to the quality of life in line with health topics has targeted many groups with specific diseases as participants. This research seeks to understand employees' quality of life affected by COVID-19, who worked from home as a healthy group experiencing psychological distress and those who were sick. Internal and external variables were involved in gaining a better understanding of employees' quality of life phenomena. Based on the theoretical arguments that have been put forward, this study assumes that there is an influence of type D personality, anxiety, technology overload, and work-life balance on employees' quality of life who worked from home during the COVID-19 pandemic.

\section{METHOD}

Participants in this study were 486 people, consisting of 152 male employees and 334 female employees who mostly worked as private employees. Most of the participants came from the Jakarta Greater area who worked from home because of the COVID-19 pandemic. The average age of participants was 34.39 years $(S D=3.86)$. Participants were reached out using purposive sampling involving online questionnaires, comprising informed consent, self-identification, and the study scales.

In the introduction section, prospective participants were given information about the required inclusion criteria and were invited to pass through the link provided if they were not included in the study or did not deign to fill out.

Quality of life in this study was measured using a scale belonging to (Burckhardt et al., 2003). This scale consisted of three aspects, namely (1) relationship and material well-being, (2) personal, social, and community commitment, and (3) health and functioning. Also, it comprised of 15 items. Beginning with the statement "How satisfied are you with the following things while working at home during the COVID-19 pandemic ....", then examples of the items would include "Health". The response categories on this scale were Very Dissatisfied to Very Satisfied, with scores ranging from 1 to 7 . This scale's reliability was $\alpha=0.958$, and the score of the average variance extracted was 0.796-0.849.

Anxiety in this study was assessed employing a scale developed by (Ahorsu et al., 2020). This scale is unidimensional, consisting of seven items. An example of this scale was "It makes me 
uncomfortable to think about coronavirus-19". On this scale, the response categories were Strongly Disagree to Strongly Agree, with a range of scores from 1 to 5. This scale's reliability was $\alpha=0.842$, and the score of the average variance extracted was 0.791-0.858.

Besides, type D personality was evaluated using a scale proposed by Denollet (2005). This scale contained two aspects: negative affectivity and social disinhibition. There were 14 items on this scale with an example, "I make contact easily when I meet people". The response categories on this scale were Very Unsuitable to Very Suitable, with a range of scores from 0 to 4. This scale's reliability was $\alpha=0.919$, and the score of the average variance extracted was $0.657-0.667$.

Technology overload in this study was calculated utilizing Choi \& Lim (2016) scale. This scale is unidimensional, consisting of four items. An example of this scale was "I am forced by this technology to do more work than I can handle". The response categories on this scale were Very Unsuitable to Very Suitable, with a range of scores from 1-5. This scale's reliability was $\alpha=0.922$, and the score of the average variance extracted was 0.9.

Furthermore, work-life balance in this study was determined employing Brough et al. (2014) scale. This scale is unidimensional, consisting of four items. It was started with the statement, "When I reflect on my work and non-work activities (your routine activities outside work such as family, friends, sports, learning, etc.), during the COVID-19 pandemic, I concluded that ......" I have difficulty balancing my work and non-work activities". The response categories on this scale were Strongly Disagree to Strongly Agree with scores ranging from 1-5. This scale's reliability was $\alpha=0.919$, and the score of the average variance extracted was 0.899 .

The main analysis technique used in this study was hierarchical regression utilizing SPSS. However, correlations were made initially to get an initial picture of the empirical relationships between variables.

\section{RESULTS AND DISCUSSION}

In Table 1, it appears that, basically, all independent variables had a significant correlation to the quality of life. The strongest correlations were seen in type D personality and quality of life, followed by anxiety, work-life balance, and technology overload.

Table 1.

Matric correlation between variables

\begin{tabular}{llllll}
\hline & $\mathbf{1}$ & $\mathbf{2}$ & $\mathbf{3}$ & $\mathbf{4}$ & $\mathbf{5}$ \\
\hline Quality of life & & & & & \\
Type D personality & $-0.752^{* *}$ & & & & \\
Anxiety & $-0.554^{* *}$ & $0.673^{* *}$ & & & \\
Technology overload & $-0.452^{* *}$ & $0.599^{* *}$ & $0.613^{* *}$ & & \\
Work-life balance & $0.502^{* *}$ & $-0.588^{* *}$ & $-0.535^{* *}$ & $-0.748^{* *}$ & \\
Mean & 55.45 & 30.06 & 21.27 & 13.20 & 11.21 \\
SD & 14.40 & 7.91 & 3.83 & 3.43 & 3.49 \\
\hline
\end{tabular}

Note: 1 = quality of life, 2 = type $\mathrm{D}$ personality, 3 = anxiety, 4 = technology overload, 5 = work-life balance

$$
{ }^{*}=p<.05,{ }^{* *}=p<.01
$$


Table 2.

Hierarchy regression from all variables to quality of life

\begin{tabular}{|c|c|c|c|c|c|c|}
\hline Variable & $\beta$ & $\mathrm{t}$ & $\mathrm{R}$ & R2 & $\Delta \mathrm{R} 2$ & $\Delta \mathrm{F}$ \\
\hline $\begin{array}{l}\text { Model } \\
\text { Type D personality }\end{array}$ & -.752 & $-25.095^{* *}$ & .752 & .565 & .656 & $629.782^{* *}$ \\
\hline $\begin{array}{l}\text { Model } 2 \\
\text { Type D personality } \\
\text { Anxiety }\end{array}$ & $\begin{array}{l}-.693 \\
-.088\end{array}$ & $\begin{array}{l}-17.158^{* *} \\
-2.180^{*}\end{array}$ & .755 & .570 & .568 & $319.708^{* *}$ \\
\hline $\begin{array}{l}\text { Model } 3 \\
\text { Type D personality } \\
\text { Anxiety } \\
\text { Technology overload }\end{array}$ & $\begin{array}{l}-.703 \\
-.100 \\
.031\end{array}$ & $\begin{array}{l}-16.501^{* *} \\
-2.301^{*} \\
.768\end{array}$ & .755 & .570 & .568 & $213.154^{* *}$ \\
\hline $\begin{array}{l}\text { Model } 4 \\
\text { Type D personality } \\
\text { Anxiety } \\
\text { Technology overload } \\
\text { Work-life balance }\end{array}$ & $\begin{array}{l}-.673 \\
-.097 \\
.117 \\
.142\end{array}$ & $\begin{array}{l}-15.563^{* *} \\
-2.263^{*} \\
2.414^{*} \\
3.068^{* *}\end{array}$ & .761 & .578 & .575 & $165.009^{* *}$ \\
\hline
\end{tabular}

Table 2 shows several important things, especially from the magnitude of anxiety and technology overload's influences on quality of life. When performing regression, the influence of anxiety became reduced and was not too large compared to other variables. Likewise, technology overload, although significant, had a positive effect on the quality of life.

The magnitude of type D personality's effect on the quality of life can be understood. A study of Staniute et al. (2015) affirmed that the large direct influence of type D personality often makes various mediator variables less powerful in affecting the quality of life. It can occur because both aspects of personality type $\mathrm{D}$, namely negative affectivity and social inhibition, make individuals create psychological distance in social relations and provide personal pressure that harms their mental health (Denollet, 2005). This situation is bad for the quality of life, not only for individuals who are already physically ill but also for physically healthy groups (Stevenson \& Williams, 2014). The magnitude of type $\mathrm{D}$ personality's impact on the quality of life can also be caused by a lack of social support (Li et al., 2017). In this COVID-19 study, most participants were married, and the majority claimed their partners also worked. It indicated that social support from spouses was indeed difficult to obtain because they both carried out work from home activities so that they should independently handle and balance the conditions between work and household.

Besides, the community lives during the COVID-19 pandemic with the possibility of contracting the virus. Such conditions are prone to cause anxiety. Meanwhile, this anxiety condition is related to aspects of health, financial problems, work, and the social presence of individuals in the family and friendship, which affects the perceived quality of life (Camacho-Alonso et al., 2018). The finding that the anxiety's effect on the quality of life was not as great as the other three independent variables' influences showed that demographic factors such as a large number of participants with an education level at the undergraduate and postgraduate level were likely to have an indirect role in reducing the effect. Yen et al. (2011) asserted that demographic factors could reduce the influence of anxiety on quality of life. The thing causing the influence of anxiety on COVID-19 on the quality of life to be less dominant was the possibility that participants have adapted their anxiety level. In this case, time makes the psychological state of anxiety increasingly mild and flexible (Davis et al., 2020).

Moreover, the finding that technology overload positively influenced employees' quality of life is essential to be discussed further. Work from home situations made employees who did 
not have the skills to work using technology became forced to learn. Meanwhile, employees who were used to using technology while working were also encouraged to maximize their skills. The use of technology helps optimize the process of higher-order individual thinking skills (DarlingHammond et al., 2020). It signified that employees understood technology as a means to learn new things, and in the process, employees felt that they were developing intellectually when working using technology. Intellectual development is one aspect considered in the quality of life (Burckhardt et al., 2003).

At this point, individuals experience technology readiness. Technology readiness describes an individual's positive perspective on technology that is seen to help achieve goals in life and complete existing work (Kim et al., 2020). The biggest challenge for technology readiness is the discomfort problem where there is a lack of knowledge in using technology (Lu \& Hayes, 2012; Sunny et al., 2019). Nevertheless, for employees working from home, the technology used is most likely the technology commonly encountered when working in the office so that the discomfort problem is not too much of an obstacle. As long as the time management of using technology when work from home can be done even though the workload is with heavy technology, the quality of life can still be achieved.

On the other hand, the platform used for work can be a system that is indeed developed by the company or organization concerned, or even through social media (Caruso, 2018; Park et al., 2017). The use of social media is considered to facilitate communication and improve employees' performance even though they work online (Park et al., 2017). It happens because the use of technology is accepted and positively perceived as things that can be used to make work more effective (Campbell \& Roberts, 2019). The individual then becomes fully aware that when work is hampered due to his inability to use technology, the problems encountered when working from home become increasingly complex. It means that the individual then views that the use of technology, even though it may feel heavy and time-consuming, affects the completion of work better. Therefore, when work can be completed, the physical and psychological burden decreases, affecting the perceived quality of life.

This research's findings indicated that work-life balance had a significant positive effect on life quality. Balance in meeting the demands between work and fulfilling roles in the family does help individuals get a better quality of life (Lee \& Sirgy, 2018; Nigade \& Bhola, 2016; Sirgy \& Lee, 2016). Otherwise, work pressure is often seen as a role enrichment that is useful for developing individual abilities in handling various other matters such as family (Lee \& Sirgy, 2018; Nigade \& Bhola, 2016; Sirgy \& Lee, 2016). Besides, individuals also consider health as critical in helping them balance their role in work and as family members, where health is also a crucial factor in the quality of life (Gragnano et al., 2020). The findings of Yang et al. (2018) stated that poor work-life balance reflects the lack of independence in work and endurance to work for a long duration. It indicates that when an individual can create work-life balance, he will be more effective in handling the burden when working at home. Therefore, when much work can be done optimally, individuals will release tension and get a better quality of life.

Overall, this research's findings can be explained using the quality of life theory developed by (Zhan, 1992). Zhan (1992) explained that the quality of life perceived by individuals is the result of the perceived involvement of personal factors, health factors, and sociocultural factors. In this case, cognition role in embracing these three factors is crucial in shaping positive and negative perceptions, which affect the quality of life. Zhan (1992) quality of life concept is easier to explain a variety of mental health cases related to health in groups with specific ethnic and cultural emphasis (Bhandari et al., 2017). 
Further, type $\mathrm{D}$ personality is a factor closely related to health because this personality type also determines individuals' vulnerability to experiencing psychological and physical problems due to certain diseases (Mols \& Denollet, 2010). Meanwhile, the personal setting factor is represented by anxiety that originates from within a person. On the other hand, sociocultural factors are represented using technology, which creates pressure when working from home, and work-life balance is a unique factor in every household but is strongly influenced by the culture's role. These three factors contribute to the quality of life felt by employees who work from home during the COVID-19 pandemic. Zhan (1992) emphasized the importance of the surrounding environment's role in helping individuals perceive personal, health, and sociocultural factors that affect perceived quality of life. The environment's role also helps individuals adapt to the difficult conditions that must be passed to get quality of life (Johari \& Marzuki, 2013). It also accommodates why technology overload was perceived differently by participants so that it had a positive influence on the quality of life.

\section{CONCLUSION}

Based on the findings obtained in this study, several conclusions can be drawn. First, as with previous research findings, internal factors, such as type D personality, still play a dominant role in influencing the quality of life. Second, anxiety related to COVID-19 did not really affect employee's quality of life who worked from home compared to more contextual factors, such as technology overload and work-life balance that were directly related to the participants' daily lives in the family. Third, technology overload is only a problem in the level of workload perception. However, when viewed as a necessity and an opportunity for learning and survival, it increased the quality of life.

\section{REFERENCES}

Ahmed, M. Z., Ahmed, O., Aibao, Z., Hanbin, S., Siyu, L., \& Ahmad, A. (2020). Epidemic of COVID-19 in China and associated psychological problems. Asian Journal of Psychiatry, 51, 102092. https://doi.org/10.1016/j.ajp.2020.102092

Ahorsu, D. K., Lin, C.-Y., Imani, V., Saffari, M., Griffiths, M. D., \& Pakpour, A. H. (2020). The Fear of COVID-19 Scale: Development and initial validation. International Journal of Mental Health and Addiction, 1-9. https://doi.org/10.1007/s11469-020-00270-8

Baloran, E. T. (2020). Knowledge, attitudes, anxiety, and coping strategies of students during COVID-19 pandemic. Journal of Loss and Trauma, 25(8), 635-642. https://doi.org/10.10 $80 / 15325024.2020 .1769300$

Benson, A. D., Johnson, S. D., \& Kuchinke, K. P. (2002). The use of technology in the digital workplace: A framework for human resource development. Advances in Developing Human Resources, 4(4), 392-404. https://doi.org/10.1177/152342202237518

Bhandari, S., Sriyuktasuth, A., \& Pongthavornkamol, K. (2017). Treatment-related quality of life in Nepalese women with breast cancer. Asian Pasific Journal of Cancer Prevention, 18(12), 3365-3371. https://doi.org/10.22034/APJCP.2017.18.12.3365

Bisschoff, M., Koen, V., \& Ryke, E. H. (2019). Strategies for work-family balance in a South 
African context. Community, Work \& Family, 22(3), 319-337. https://doi.org/10.1080/13 668803.2018.1473337

Brough, P., Timms, C., O’Driscoll, M. P., Kalliath, T., Siu, O.L., Sit, C., \& Lo, D. (2014). Worklife balance: A longitudinal evaluation of a new measure across Australia and New Zealand workers. The International Journal of Human Resource Management, 25(19), 2724-2744. https://doi.org/10.1080/09585192.2014.899262

Bueno, D. C. (2020). Physical distancing: A rapid global analysis of public health strategies to minimize Covid-19 outbreaks. Institutional Multidisciplinary Research and Development (IMRaD), 3(1), 31-53. https://doi.org/10.13140/RG.2.2.30429.15840/1

Burckhardt, C. S., Anderson, K. L., Archenholtz, B., \& Hägg, O. (2003). The flanagan quality of life scale: Evidence of construct validity. Health and Quality of Life Outcomes, 1, 1-7. https://doi.org/10.1186/1477-7525-1-59

Camacho-Alonso, F., Cánovas-García, C., Martínez-Ortiz, C., De la Mano-Espinosa, T., OrtuñoCeldrán, T., Marcello-Godino, J. I., Ramos-Sánchez, R., \& Sánchez-Siles, M. (2018). Oral status, quality of life, and anxiety and depression in hemodialysis patients and the effect of the duration of treatment by dialysis on these variables. Odontology, 106(2), 194-201. https://doi.org/10.1007/s10266-017-0313-6

Campbell, D. E., \& Roberts, N. (2019). Effective use of analytic DSS and job performance: Looking beyond technology acceptance. Journal of Organizational Computing and Electronic Commerce, 29(2), 125-138. https://doi.org/10.1080/10919392.2019.1571756

Caruso, S. J. (2018). Toward understanding the role of Web 2.0 technology in self-directed learning and job performance. Contemporary Issues in Education Research, 11(3), 89-97. https:// core.ac.uk/download/pdf/268592219.pdf

Choi, S. B., \& Lim, M. S. (2016). Effects of social and technology overload on psychological wellbeing in young South Korean adults: The mediatory role of social network service addiction. Computers in Human Behavior, 61, 245-254. https://doi.org/10.1016/j.chb.2016.03.032

Craske, M. G., \& Stein, M. B. (2016). Anxiety. The Lancet, 388(10063), 3048-3059. https://doi. org/10.1016/S0140-6736(16)30381-6

Darling-Hammond, L., Flook, L., Cook-Harvey, C., Barron, B., \& Osher, D. (2020). Implications for educational practice of the science of learning and development. Applied Developmental Science, 24(2), 97-140. https://doi.org/10.1080/10888691.2018.1537791

Davis, A. K., Barrett, F. S., \& Griffiths, R. R. (2020). Psychological flexibility mediates the relations between acute psychedelic effects and subjective decreases in depression and anxiety. Journal of Contextual Behavioral Science, 15, 39-45. https://doi.org/10.1016/j.jcbs.2019.11.004

Denollet, J. (2005). DS14: Standard assessment of negative affectivity, social inhibition, and type D personality. Psychosomatic Medicine, 67(1), 89-97. https://doi.org/10.1097/01. psy.0000149256.81953.49

Denollet, J., Schiffer, A. A., \& Spek, V. (2010). A general propensity to psychological distress affects cardiovascular outcomes: evidence from research on the type D (distressed) personality 
profile. Circulation: Cardiovascular Quality and Outcomes, 3(5), 546-557. https://doi. org/10.1161/circoutcomes.109.934406

Drydakis, N. (2015). The effect of unemployment on self-reported health and mental health in Greece from 2008 to 2013: A longitudinal study before and during the financial crisis. Social Science \& Medicine, 128, 43-51. https://doi.org/10.1016/j.socscimed.2014.12.025

Fiksenbaum, L. M. (2014). Supportive work-family environments: Implications for work-family conflict and well-being. The International Journal of Human Resource Management, 25(5), 653-672. https://doi.org/10.1080/09585192.2013.796314

Gragnano, A., Simbula, S., \& Miglioretti, M. (2020). Work-life balance: Weighing the importance of work-family and work-health balance. International Journal of Environmental Research and Public Health, 17(3), 907-927. https://doi.org/10.3390/ijerph17030907

Haar, J. M., Russo, M., Suñe, A., \& Ollier-Malaterre, A. (2014). Outcomes of work-life balance on job satisfaction, life satisfaction and mental health: A study across seven cultures. Journal of Vocational Behavior, 85(3), 361-373. https://doi.org/10.1016/j.jvb.2014.08.010

Huang, Y., \& Zhao, N. (2020). Mental health burden for the public affected by the COVID-19 outbreak in China: Who will be the high-risk group? Psychology, Health \& Medicine, 1-12. https://doi.org/10.1080/13548506.2020.1754438

Johari, J., \& Marzuki, N. A. (2013). Relating stress, anxiety and depression among flood victims' quality of life in Malaysia: A theoretical perspective. International Journal of Social Science and Humanity, 3(6), 543-547. https://doi.org/10.7763/ijshh.2013.V3.300

Karimi, M., \& Brazier, J. (2016). Health, health-related quality of life, and quality of life: What is the difference? PharmacoEconomics, 34(7), 645-649. https://doi.org/10.1007/s40273016-0389-9

Kim, M. J., Lee, C.-K., \& Preis, M. W. (2020). The impact of innovation and gratification on authentic experience, subjective well-being, and behavioral intention in tourism virtual reality: The moderating role of technology readiness. Telematics and Informatics, 49, 1-55. https://doi.org/10.1016/j.tele.2020.101349

Kramer, A., \& Kramer, K. Z. (2020). The potential impact of the Covid-19 pandemic on occupational status, work from home, and occupational mobility. Journal of Vocational Behavior, 119, 1-4. https://doi.org/10.1016/j.jvb.2020.103442

Lee, D.J., \& Sirgy, M. J. (2018). What do people do to achieve work-life balance? A formative conceptualization to help develop a metric for large-scale quality-of-life surveys. Social Indicators Research, 138(2), 771-791. https://doi.org/10.1007/s11205-017-1673-6

Lee, S. A. (2020). Coronavirus anxiety scale: A brief mental health screener for COVID-19 related anxiety. Death Studies, 44(7), 393-401. https://doi.org/10.1080/07481187.2020.1748481

Li, J., Wu, X., Lin, J., Zou, D., Yang, X., Cheng, S., \& Guo, Q. (2017). Type D personality, illness perception, social support and quality of life in continuous ambulatory peritoneal dialysis patients. Psychology, Health \& Medicine, 22(2), 196-204. https://doi.org/10.1080/135485 06.2016.1224371 
Lu, J., \& Hayes, L. A. (2012). How do technology readiness, platform functionally and trust influence C2C user satisfaction? Journal of Electronic Commerce Research, 13(1), 50-69.

Mols, F., \& Denollet, J. (2010). Type D personality in the general population: A systematic review of health status, mechanisms of disease, and work-related problems. Health and Quality of Life Outcomes, 8(1), 1-10. https://doi.org/10.1186/1477-7525-8-9

Nigade, J., \& Bhola, S. (2016). Relationship between work life balance, quality of work life and quality of life of women working in service industry. Pravara Management Review, 15(1), $30-45$.

O’Riordan, A., Howard, S., \& Gallagher, S. (2020). Type D personality and life event stress: The mediating effects of social support and negative social relationships. Anxiety, Stress, \& Coping, 33(4), 452-465. https://doi.org/10.1080/10615806.2020.1746284

Park, J. Y., Im, I., \& Sung, C.S. (2017). Is social networking a waste of time? The impact of social network and knowledge characteristics on job performance. Knowledge Management Research \& Practice, 15(4), 560-571. https://doi.org/10.1057/s41275-017-0071-9

Ping, W., Zheng, J., Niu, X., Guo, C., Zhang, J., Yang, H., \& Shi, Y. (2020). Evaluation of healthrelated quality of life using EQ-5D in China during the COVID-19 pandemic. Plos One, 15(6), 1-12. https://doi.org/10.1371/journal.pone.0234850

Sirgy, M. J., \& Lee, D.J. (2016). Work-life balance: A quality-of-life model. Applied Research in Quality of Life, 11(4), 1059-1082. https://doi.org/10.1007/s11482-015-9419-6

Staniute, M., Brozaitiene, J., Burkauskas, J., Kazukauskiene, N., Mickuviene, N., \& Bunevicius, R. (2015). Type D personality, mental distress, social support and health-related quality of life in coronary artery disease patients with heart failure: A longitudinal observational study. Health and Quality of Life Outcomes, 13(1), 1-11. https://doi.org/10.1186/s12955014-0204-2

Stevenson, C., \& Williams, L. (2014). Type D personality, quality of life and physical symptoms in the general population: A dimensional analysis. Psychology \& Health, 29(3), 365-373. https://doi.org/10.1080/08870446.2013.856433

Sunny, S., Patrick, L., \& Rob, L. (2019). Impact of cultural values on technology acceptance and technology readiness. International Journal of Hospitality Management, 77(1), 89-96. https://doi.org/10.1016/j.ijhm.2018.06.017

Tams, S., Ahuja, M., Thatcher, J., \& Grover, V. (2020). Worker stress in the age of mobile technology: The combined effects of perceived interruption overload and worker control. The Journal of Strategic Information Systems, 29(1), 101595. https://doi.org/10.1016/j.jsis.2020.101595

Tarafdar, M., Tu, Q., Ragu-Nathan, B. S., \& Ragu-Nathan, T. S. (2007). The impact of technostress on role stress and productivity. Journal of Management Information Systems, 24(1), 301-328. https://doi.org/10.2753/MIS0742-1222240109

Tarafdar, M., Tu, Q., \& Ragu-Nathan, T. S. (2010). Impact of technostress on end-user satisfaction and performance. Journal of Management Information Systems, 27(3), 303-334. https://doi. org/10.2753/MIS0742-1222270311 
Tomasi, J., Zack, M., \& Kennedy, J. L. (2019). Outside the typical anxiety disorder definition: Characterizing the role of impulsivity in comorbid substance use disorder. Personalized Medicine in Psychiatry, 13-21. https://doi.org/10.1016/j.pmip.2019.04.001

Torales, J., O’Higgins, M., Castaldelli-Maia, J. M., \& Ventriglio, A. (2020). The outbreak of COVID-19 coronavirus and its impact on global mental health. International Journal of Social Psychiatry, 66(4), 317-320. https://doi.org/10.1177/0020764020915212

Wagner, D. T., Barnes, C. M., \& Scott, B. A. (2014). Driving it home: How workplace emotional labor harms employee home life. Personnel Psychology, 67(2), 487-516. https://doi. org/10.1111/peps. 12044

Wang, Yanbo, Zhao, X., Feng, Q., Liu, L., Yao, Y., \& Shi, J. (2020). Psychological assistance during the coronavirus disease 2019 outbreak in China. Journal of Health Psychology, 25(6), 733-737. https://doi.org/10.1177/1359105320919177

Wang, Yenan, Di, Y., Ye, J., \& Wei, W. (2020). Study on the public psychological states and its related factors during the outbreak of coronavirus disease 2019 (COVID-19) in some regions of China. Psychology, Health \& Medicine, 1-10. https://doi.org/10.1080/1354850 6.2020 .1746817

WHO. (2020). Coronavirus disease 2019 (COVID-19) world health situation report. Retrieved from https://www.who.int/emergencies/diseases/novel-coronavirus-2019/situation-reports

Williams, L., \& Wingate, A. (2012). Type D personality, physical symptoms and subjective stress: The mediating effects of coping and social support. Psychology \& Health, 27(9), 1075-1085. https://doi.org/10.1080/08870446.2012.667098

Wood, J., Oh, J., Park, J., \& Kim, W. (2020). The relationship between work engagement and work-life balance in organizations: A review of the empirical research. Human Resource Development Review, 19(3), 240-262. https://doi.org/10.1177/1534484320917560

Xiang, Y.T., Yang, Y., Li, W., Zhang, L., Zhang, Q., Cheung, T., \& Ng, C. H. (2020). Timely mental health care for the 2019 novel coronavirus outbreak is urgently needed. The Lancet Psychiatry, 7(3), 228-229. https://doi.org/10.1016/S2215-0366(20)30046-8

Yang, J. W., Suh, C., Lee, C. K., \& Son, B. C. (2018). The work-life balance and psychosocial wellbeing of South Korean workers. Annals of Occupational and Environmental Medicine, 30(1), 1-7. https://doi.org/10.1186/s40557-018-0250-z

Yen, C.F., Yang, P., Ko, C.H., Yen, J.Y., Hsu, F.C., \& Wu, Y.Y. (2011). The relationships between quality of life and anxiety symptoms and the moderating effects of socio-demographic characteristics in Taiwanese adolescents. Quality of Life Research, 20(7), 1071-1078. https:// doi.org/10.1007/s11136-010-9843-x

Zhan, L. (1992). Quality of life: Conceptual and measurement issues. Journal of Advanced Nursing, 17(7), 795-800. https://doi.org/10.1111/j.1365-2648.1992.tb02000.x 